\title{
From T cell "exhaustion" to anti-cancer immunity
}

\author{
Grégory Verdeil ${ }^{1}$, Silvia A. Fuertes Marraco ${ }^{1}$, Timothy Murray ${ }^{1}$ and Daniel E. Speiser ${ }^{1}$ \\ ${ }^{1}$ Ludwig Cancer Research Center and Department of Oncology, Clinical Tumor \\ Biology \& Immunotherapy Group, Lausanne University Hospital Center (CHUV) and \\ University of Lausanne, Route de la Corniche 9A, CH-1066 Epalinges, Switzerland.
}

\begin{abstract}
Abbreviations: AHR, aryl-hydrocarbon receptor; APC, antigen-presenting cells; BTLA, Band T-lymphocyte attenuator; BV, hepatitis B virus; CTL, cytotoxic T lymphocytes; CTLA-4, cytotoxic T lymphocyte antigen 4; DC, dendritic cell; FOXP-1, Forkhead box protein P1; $\mathrm{HCV}$, hepatitis $\mathrm{C}$ virus; HIF1 $\alpha$, Hypoxia Induced Factor 1 alpha; HIV, human immunodeficiency virus; HLA, human leukocyte antigen; HVEM, Herpesvirus entry mediator; IDO, Indoleamine 2,3-dioxygenase; IFN $\gamma$, interferon gamma; IL-2, interleukin-2; ITIM, Immunoreceptor tyrosine-based inhibitory motif; KIR, Killer-cell immunoglobulin-like receptors; LAG-3, lymphocyte-activation gene 3; LCMV, lymphocytic choriomeningitis virus; MHC, major histocompatibility complex; NK cell, natural killer cell; NSCLC, squamous non-small cell lung cancer; PBMC, peripheral blood mononuclear cells; PD-1, programmed cell death 1; PD-L1/PD-L2, programmed cell death ligand 1/2; RNAseq, RNA sequencing; shRNA, short hairpine RNA; TCR, T cell receptor; TGF $\beta$, transforming growth factor beta; TIGIT, T cell immunoreceptor with Ig and ITIM domains; TILs, tumor infiltrating lymphocytes; TME, tumor microenvironment; TNF $\alpha$, tumor necrosis factor alpha; Treg, regulatory T cells; VHL, Von-Hippel Lindau tumor suppressor

* Corresponding author. Tel.:+41213140182; fax:+41213147477.

E-mail address: doc@dspeiser.ch
\end{abstract}




\begin{abstract}
The immune system has the potential to protect from malignant diseases for extended periods of time. Unfortunately, spontaneous immune responses are often inefficient. Significant effort is required to develop reliable, broadly applicable immunotherapies for cancer patients. A major innovation was transplantation with hematopoietic stem cells from genetically distinct donors for patients with hematologic malignancies. In this setting, donor T cells induce longterm remission by keeping cancer cells in check through powerful allogeneic graft-versusleukemia effects. More recently, a long awaited breakthrough for patients with solid tissue cancers was achieved, by means of therapeutic blockade of $\mathrm{T}$ cell inhibitory receptors. In untreated cancer patients, $\mathrm{T}$ cells are dysfunctional and remain in a state of $\mathrm{T}$ cell "exhaustion". Nonetheless, they often retain a high potential for successful defense against cancer, indicating that many $\mathrm{T}$ cells are not entirely and irreversibly exhausted but can be mobilized to become highly functional. Novel antibody therapies that block inhibitory receptors can lead to strong activation of anti-tumor $\mathrm{T}$ cells, mediating clinically significant anti-cancer immunity for many years. Here we review these new treatments and the current knowledge on tumor antigen-specific T cells.
\end{abstract}

\title{
Keywords:
}

T cells; exhaustion; tumor microenvironment; cancer biology; cancer immunotherapy; clinical trials 


\section{Table of contents}

1. The current state of clinical immunotherapy for patients with solid tissue cancers ....................... 4

2. Cytotoxic CD8 T cells and CD4 T helper-1 cells in cancer patients .......................................... 5

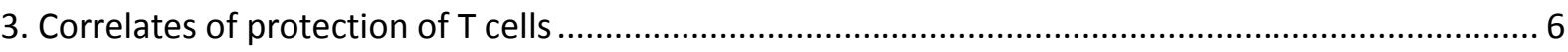

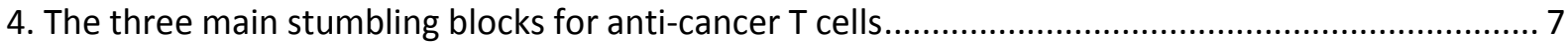

4.1 Limited repertoire of naïve T cells specific for tumor antigens ........................................... 7

4.2 T cell activation in cancer patients: too little, too late ................................................. 7

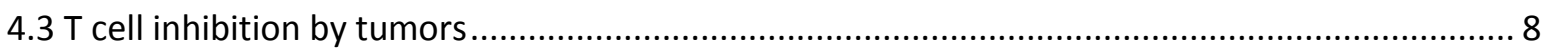

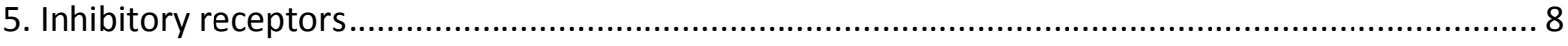

6. Signaling and transcriptional regulation in "exhausted" T cells............................................... 10

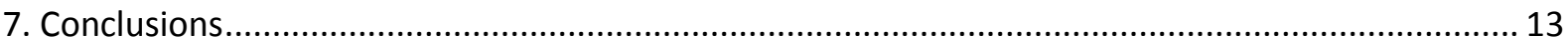

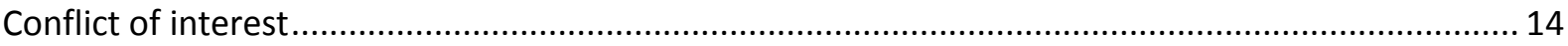

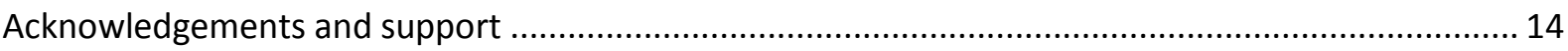

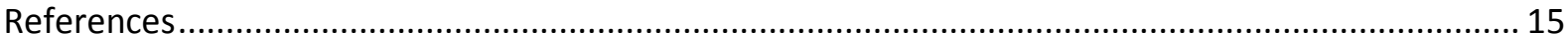




\section{The current state of clinical immunotherapy for patients with solid tissue cancers}

In the quest to develop effective therapies for cancer, it is not surprising that harnessing the capacity of the immune system is at the forefront. Immunity to infectious disease has revealed the profound potency and specificity for protection against microbial pathogens. Moreover, the mechanisms underlying immunological memory and long-term immune surveillance of pathogens are increasingly well-understood [1-6]. Compared to clearing infections, the immune system is less powerful against cancer, and tumors frequently overcome immune defense mechanisms. Nonetheless, some patients mount a robust anti-cancer immune response that successfully keeps malignant disease in check. In such cases there is a good likelihood that immune protection lasts for years. This first became apparent in patients with hematological malignancies, treated by allogeneic hematopoietic stem cell transplantation $[7,8]$. In these patients, immune cells from the donor can efficiently eliminate cancer cells, and they continue to do so over many years through so-called graft-versus-leukemia effects, as demonstrated by detailed monitoring of immune cell activity and molecular quantification of (minimal) residual disease.

The graft-versus-leukemia effect is driven by alloantigens (transplantation antigens), which are well known to induce strong $\mathrm{T}$ cell responses. In the absence of alloantigens (i.e. in patients not having received an allograft) other drivers are needed in order to set the immune system in action against cancer. The seminal discoveries of inhibitory lymphocyte receptors have given rise to the concept of immune 'checkpoints'. Alleviating the suppressive effects of these receptors can lead to powerful immune activation. Indeed, therapeutic blockade of inhibitory immune receptors has recently led to major breakthroughs in clinical oncology. Based on numerous independent studies illustrating the powerful role of the receptor CTLA-4 (Cytotoxic T Lymphocyte Antigen 4) in the inhibition of T cell responses [9-14], a number of clinical trials were launched to determine whether CTLA-4-blocking monoclonal antibodies could enhance the activity of tumor specific $\mathrm{T}$ cells and provide clinical benefit to melanoma patients. Two pivotal phase 3 clinical trials $[15,16]$ demonstrated prolongation of patient survival upon treatment with the anti-CTLA-4 monoclonal antibody, Ipilimumab (Yervoy, Bristol-Myers Squibb), leading to FDA approval in March 2011. Long-term results were provided very recently in a key paper reporting follow-up data for up to 12 years of 1861 melanoma patients treated with Ipilimumab in 10 clinical trials [17]. The 3-year overall survival rate was $22 \%$. Interestingly, a prominent tail end of the survival curve was observed, beginning at approximately 3 years (which was independent of prior therapy or Ipilimumab dose; 3 or $10 \mathrm{mg} / \mathrm{kg}$ ). This demonstrates that Ipilimumab treatment is highly successful with regard to long-term durability, consistent with the unique "memory" potential of the immune system. This observation contrasts to the relatively short-term effects of the majority of other treatments for patients with metastatic cancer. Surgery, chemotherapy, radiotherapy and targeted therapies (e.g. tyrosine kinase inhibitors) may prolong survival for several months, but most patients experience cancer recurrence or progression despite repetitive treatment.

Only a few years after the introduction of anti-CTLA-4 therapy for melanoma patients, a second immune inhibitory receptor became a prime therapeutic target for patients with solid tissue cancers. Several studies demonstrated that Programmed cell Death-1 (PD-1) and its ligands PD-L1 and PD-L2 play crucial roles in the inhibition of T cell responses $[18,19]$. In addition, antibody-mediated blockade of PD-1 can induce anti-tumor immune responses in animal models [20,21]. Intensive clinical development led to the demonstration that blocking 
the PD1/PDL1 axis may provide clinical benefit for cancer patients. In 2014, the first anti-PD1 antibodies were approved in Japan (Nivolumab-Opdivo, Bristol-Myers Squibb/Ono Pharmaceuticals) and the USA (Pembrolizumab-Keytruda, Merck \& Co.) for patients with previously treated advanced metastatic melanoma. Recently, a randomized study compared treatment of advanced melanoma patients with Pembrolizumab versus Ipilimumab and found that the former prolonged progression-free and overall survival with fewer high-grade adverse events [22]. A very important advance came with recent evidence that anti-PD-1 and anti-PDL1 antibodies are not only beneficial for melanoma patients, but also for patients with several common carcinomas such as non-small cell lung cancer, renal cell cancer, ovarian cancer, head and neck cancer, bladder cancer, gastric cancer and mesothelioma [23,24] (reviewed in [25]). The PD-1 specific antibody Nivolumab received FDA approval in March 2015 for the treatment of patients with squamous non-small cell lung cancer (NSCLC), the first treatment approval beyond melanoma. Currently, a large number of clinical trials evaluate the use of antibodies targeting the inhibitory receptors/ligands CTLA-4, PD-1, PD-L1, LAG-3 (Lymphocyte Activation Gene-3) and a KIR (Killer cell Immunoglobulin-like Receptor) for the treatment of patients with diverse cancers (clinicaltrials.gov and reviewed in [26,27]). Some of these drugs and approaches are already in phase 3 trials, often based on robust results from early phase clinical trials. It is therefore likely that these reagents will become approved and, thus, become broadly available for cancer patients during the next few years. Moreover, very promising results (with significantly increased patient survival) have been obtained with the combination of anti-CTLA-4 and anti-PD-1 antibodies. Even though the autoimmune toxicities are increased and thus considerable, they are manageable with prompt and proper diagnostic and therapeutic follow-up [25,28].

\section{Cytotoxic CD8 T cells and CD4 T helper-1 cells in cancer patients}

Based on numerous mouse studies, research in cancer patients has increasingly focused on $\mathrm{T}$ cells. Disease-driven activation of $\mathrm{T}$ cells in melanoma patients has been demonstrated by several studies [29,30]. Although human cancers of almost any kind may induce $\mathrm{T}$ cell responses, these are typically insufficient for counteracting tumor progression. Essential information was obtained from studies of the human tumor microenvironment: a metaanalysis published by Fridman et al. [31] provided an interesting overview of the relationship between $\mathrm{T}$ cells that infiltrate tumors and the clinical outcome of patients. This analysis shows that increased frequencies of differentiated CD8 $\mathrm{T}$ cells (CD8+ CD45RO+) in tumors correlate widely (58 of 60 studies) with favorable clinical outcome. A similar observation was made for CD4 T helper-1 (Th1) cells, in 14 of 15 studies. Other T cell types such as Th2, Th17 and regulatory $\mathrm{T}$ cells (Tregs) showed variable correlations with prognosis across different studies. Since these studies were performed in patients with carcinomas from many different organs (such as lung, kidney, liver, stomach, colon, pancreas, breast, ovary, prostate, bladder, head \& neck and esophagus), the data emphasize a strikingly broad and "uniform" principle: CD8+ CTL and Th1 tumor infiltration are decisive factors in a very broad array of malignant diseases, irrespective of tissue location and molecular landscape. In fact, molecular and mechanistic research in cancer has revealed an overwhelming heterogeneity between patients, since many biological features such as mutated oncogenes and tumor suppressor genes or inflammatory and angiogenesis mechanisms differ even among patients with precisely the same clinical diagnosis and staging. Moreover, tumor heterogeneity is actually frequently observed within individual patients, and this includes heterogeneity among the cruxes of the disease such as oncogenic driver mutations and therapy escape mechanisms 
[32,33]. In light of this enormous degree of heterogeneity, the "uniform" principle by which CTL and Th1 cells confer protection is surprising and certainly deserves more detailed study. Prominent hypotheses currently under investigation include (i) broad epitope-targeting and (ii) long-term efficacy. Firstly, (i) the immune system can act against a broad array of "targets" (antigens) and may, thus, greatly limit opportunities for cancer cell escape in comparison to other natural or therapeutic means of protection. And second, (ii) the long-term activity of the immune system may be critical to effectively fight against aggressive malignant diseases which usually persist life-long, even if only at low (minimal residual) disease levels. In any case, the indication that immunotherapies are broadly applicable to cancers of diverse origin and molecular basis is in line with the positive prognostic impact of CTL and Th1 cell infiltration consistently observed in solid cancers.

\section{Correlates of protection of T cells}

For basic and applied ("translational") research, it has been very informative to characterize anti-cancer $\mathrm{T}$ cells in detail. However, there is no simple way to know whether a given $\mathrm{T}$ cell response translates to protective immunity of the host. $\mathrm{T}$ cells can be activated in different ways, and only some of them may protect from disease. Numerous studies have focused on "correlates of protection", in order to identify those features of T cells that can be used to distinguish useful from irrelevant immune responses. Several key properties of $\mathrm{T}$ cells are associated with protection from infectious and malignant disease (Figure 1). First, antigenspecific $\mathrm{T}$ cells must be activated and reach high frequencies, with individual $\mathrm{T}$ cells being capable of exerting multiple functions. This implies differentiation into numerous and powerful effector cells. Second, they should strongly interact with antigen-presenting cells (APCs) and target tumor cells, based on a T cell receptor (TCR) affinity and overall avidity that allows efficient recognition of tumor antigen at its naturally low levels (in contrast to the high antigen concentrations that are usually used in laboratory assays). Third, $T$ cells need to migrate throughout the body and localize to sites of disease. Forth, T cells specific for a given epitope should consist of multiple clonotypes rather than only one or very few, whose proliferative and survival potential may expire after a few months. Moreover, T cell responses should target multiple epitopes, restricted by multiple HLA alleles, in order to prevent outgrowth of tumor cells by escape mechanisms involving antigen or MHC downmodulation. Multi-epitope targeting also provides protection from other escape mechanisms such as oncogene or tumor suppressor gene alterations. Finally, T cell responses should build an immunological memory and thus persist long-term, such that residual disease is kept under control in the long-term. These properties may represent a simplified view of protective $\mathrm{T}$ cell responses, and further criteria may be important. Nevertheless, the assessment and evaluation of these criteria can be of great help in distinguishing between powerful and ineffective $\mathrm{T}$ cell responses, an essential endeavor for basic and applied research, as well as for the continued development of immunotherapy in clinical trials.

Recently, important new results were published regarding the second criterion listed above, i.e. TCR affinity and $\mathrm{T}$ cell avidity. These parameters are typically low or intermediate for non-mutated self/tumor antigens, thus compromising protective immune responses. Novel techniques such as RNAseq and highly multiplexed tetramer assays are increasingly being used to predict and physically identify neo-epitopes encoded by somatic mutations in cancer cells [34]. Neo-antigens may be recognized by $\mathrm{T}$ cells with high affinity TCRs, because immune tolerance mechanisms such as thymic deletion have not depleted these cells, in 
contrast to self-specific $\mathrm{T}$ cells with high affinity TCRs. Interestingly, there is increasing evidence that patients bearing tumors with high mutational rates and consequently large numbers of neo-epitope specific T cells are more likely to respond to immunotherapy [35-39]. Thus, the presence of critical numbers of neo-antigens and corresponding high avidity $\mathrm{T}$ cells may be a major correlate of protection.

\section{The three main stumbling blocks for anti-cancer T cells}

Despite evidence for spontaneous immune activation, the immune system most frequently fails to protect patients with metastatic cancers. Although medical progress is considerable and the efficacy of immunotherapy is increasing, improved and widely applicable therapies are still urgently needed. Further research is therefore necessary, particularly with regard to T cells in cancer.

In the majority of patients, it appears that anti-cancer $\mathrm{T}$ cell responses offer too little, too late. We recently reviewed the underlying reasons for this by describing the "Three main stumbling blocks for anti-cancer T cells" [40] which we briefly summarize below. In fact, when comparing "anti-cancer $\mathrm{T}$ cells" (essentially tumor antigen-specific CTLs and Th1 cells) with anti-viral $\mathrm{T}$ cells, one can identify three principle obstacles where the former encounter serious limitations.

\subsection{Limited repertoire of naïve T cells specific for tumor antigens}

The first stumbling block is encountered during thymic maturation. While mature naïve virusspecific T cells are 'non-self'-specific and are generally positively selected in the thymus, $\mathrm{T}$ cells specific for tumor antigens are primarily 'self'-specific and, therefore, are negatively selected by thymic clonal deletion. The result is that the naïve repertoire of mature circulating anti-cancer $\mathrm{T}$ cells in mice and humans is narrow, with low frequencies of specific cells and only low-to-intermediate TCR affinities. Such low affinity and precursor frequencies imply significant limitations for $\mathrm{T}$ cell priming and target cell lysis. As mentioned above, it is assumed that this limitation may not (or to a lesser extent) apply to mutated neo-antigens.

\subsection{T cell activation in cancer patients: too little, too late}

The second stumbling block involves the initiation and establishment of an immune response. In acute viral infections, immune responses are often fulminant and profound. Here, the sophisticated cascades of immune activation become fully engaged, thereby enabling strong clonotypic expansion of virus specific $\mathrm{T}$ cells with powerful generation of memory and effector cells. In contrast, cancers do not trigger strong immune responses, because they evolve much more slowly and lack appropriate $\mathrm{T}$ cell co-stimulatory signals, remaining "invisible" to the immune system for a long time. Furthermore, some tumors are capable of T cell tolerization, thus dampening potential responses. Consequently, tumor immune responses arise late, only when cancers start to significantly impact on tissue integrity and cause inflammation. This is often too late and too weak to win the race between the pathological process and the immune response. 


\subsection{T cell inhibition by tumors}

The third stumbling block is encountered in the tumor microenvironment (TME). Therein, anti-cancer $\mathrm{T}$ cells are usually not fully functional. Rather, they exhibit a decreased capacity to migrate and to exert effector functions against tumor cells. Their cytotoxic activity and cytokine production is attenuated as compared to acute infections. Multiple factors in the TME contribute to this attenuation (reviewed in [40-47]). Similar to unresolved (chronic) viral infections such as human immunodeficiency virus (HIV) or hepatitis, the immune response is mitigated and establishes an equilibrium of immune activation and attenuation. Understanding the mechanisms that regulate this dysfunctional state will aid the development of new strategies to increase the efficiency of immunotherapy.

Research in immune inhibition in the TME has become very widespread. It deals with multiple mechanisms exerted by various inhibitory immune cell types, and many different soluble factors and receptors. These factors may directly inhibit immune defense mechanisms, or disrupt immune activatory pathways. Due to space limitations we cannot cover the entire field and therefore refer to the literature [40-47]. In this review, we will focus on two areas, namely (i) inhibitory lymphocyte receptors, and (ii) $\mathrm{T}$ cell signaling and transcriptional regulation.

\section{Inhibitory receptors}

Most of the knowledge about molecular mechanisms that interfere with effective $\mathrm{T}$ cell responses has been learned from chronic viral infections. In this setting, $\mathrm{T}$ cells become dysfunctional and acquire a state of "exhaustion" [48], as thoroughly characterized in mice infected with a particular strain (clone 13) of lymphocytic choriomeningitis virus (LCMV) $[49,50]$. In parallel, $\mathrm{T}$ cells have been characterized in human chronic infections, such as human immunodeficiency virus (HIV) [51-53], hepatitis B virus (HBV), hepatitis C virus $(\mathrm{HCV})$, and herpes viruses. In each of these infections, the initial $\mathrm{T}$ cell response generates large numbers of virus-specific effector $\mathrm{T}$ cells, following a kinetic that is somewhat comparable to acute infection. However, with prolonged exposure to high antigen doses, the majority of these $\mathrm{T}$ cells acquire a phenotype that strongly differs from $\mathrm{T}$ cells that dominate during acute responses. As compared to their acutely responding counterparts, $\mathrm{T}$ cells produce little or no effector cytokines (interleukin-2 (IL-2), tumor necrosis factor $\alpha$ (TNF $\alpha$ ), and interferon $\gamma(\operatorname{IFN} \gamma)$ ), and show a reduced capacity for survival and re-expansion. These functional alterations are generally accompanied by high level expression of inhibitory receptors such as PD-1, T cell immunoglobulin and mucin domain-containing 3 (TIM-3), LAG-3, B- and T-lymphocyte attenuator (BTLA), cytotoxic T lymphocyte attenuator 4 (CTLA-4), CD160 or/and 2B4 [48]. Expression of most of these inhibitory receptors has also been observed on human tumor infiltrating lymphocytes (TILs) [54,55], in parallel to the observation that TILs are poor cytokine producers in vivo [56].

Frequently, inhibitory receptor expression is erroneously interpreted as a marker of $\mathrm{T}$ cell "exhaustion". This interpretation is misleading because inhibitory receptors are also often expressed by activated and differentiated $\mathrm{T}$ cells. Even naïve $\mathrm{T}$ cells can express some inhibitory receptors (e.g. BTLA and TIM-3). More importantly, T cell activation leads to strong upregulation of several inhibitory receptors (PD-1, CTLA-4, TIM-3, LAG-3, 2B4), and the majority of those listed above are expressed by differentiated effector T cells. Thus, whilst 
inhibitory receptors may be associated with $\mathrm{T}$ cell suppression in some settings, this finding does not represent the complete picture [57]. Interestingly, $T$ cells isolated from tumor lesions expressing either PD-1 or BTLA were found to represent clonally expanded tumor reactive T cells that mediated tumor regression upon $\mathrm{T}$ cell adoptive transfer into melanoma patients $[58,59]$.

For a more complete understanding, $\mathrm{T}$ cells should be analyzed beyond their expression of "markers", for example by molecular and functional characterization. Gene expression profiling of tumor antigen-specific $\mathrm{T}$ cells has demonstrated significant overlap between TILs and $\mathrm{T}$ cells in chronic infection, substantiating the concept that $\mathrm{T}$ cell "exhaustion" also occurs in cancer [54]. Inhibitory receptors may act via several mechanisms. Though still poorly understood, it seems likely that inhibitory receptors participate in supramolecular complex formation at the $\mathrm{T}$ cell surface, potentially interfering with the TCR and costimulatory receptors [60]. Inhibitory receptors may also function through common and nonredundant signaling pathways to dampen TCR and other signaling pathways (Figure 2). Mechanisms of action of these molecules are described for CTLA-4 (recruitment of the phosphatases PP2A and SHP-2), and PD-1 (recruitment of SHP-1 and SHP-2) (reviewed in [61]). These phosphatases dampen proximal TCR signaling as well as phosphorylation of the kinases downstream of the TCR, such as PI3K and AKT. For other inhibitory receptors, the mode of action remains unclear. TIM-3 inhibitory action is regulated through its association with BAT3, which binds to the cytoplasmic tail of TIM-3 and inhibits its signaling [62]. Recently CEACAM-1 (CD66a), another inhibitory receptor capable of recruiting the phosphatase SHP-1, has been shown to interact with TIM-3 and to play a central role in its expression and inhibitory function [63]. BTLA (CD272) belongs to the CD28/B7 family of immunoglobulin-like molecules and is widely expressed by lymphocytes. In contrast to most other inhibitory receptors, BTLA is downregulated with progressive differentiation to effector cell status. Nevertheless, BTLA was found to be highly expressed on differentiated tumor antigen-specific CD8 $\mathrm{T}$ cells from metastatic lymph nodes of melanoma patients. Additionally, its ligand HVEM (Herpes Virus Entry Mediator) is also present at the surface of melanoma cells [64]. TIGIT, an inhibitory receptor containing an ITIM domain on its intracytoplasmic tail, has recently been described to be expressed on CD4 and CD8 T cells in chronic infection, as well as within solid tumors in mouse and human. The inhibitory mechanisms regulated by TIGIT are not yet clearly established. It was shown that TIGIT interaction with the co-stimulatory molecule CD226 is key for inhibitory function [65]. Another study has described a ligand for TIGIT that is expressed by DCs (PVR) and which may also participate to this inhibition by rendering DCs more tolerogenic [66]. LAG-3 (CD223) binds to MHC class II molecules and shows high similarity with CD4, but it harbors a unique cytoplasmic tail containing a KIEELE motif regulating its down-stream signaling and inhibitory function in $\mathrm{T}$ cells [67]. Expression of other surface molecules like 2B4 (CD244) and CD160 has also been described on TILs and may underlie inhibitory functions in $\mathrm{T}$ cells.

The diverse modes of action of inhibitory receptors support therapy combinations with multiple blocking antibodies to increase $T$ cell responses to cancer. Several attempts have been made to combine those antibodies, showing promising results in mouse models and more importantly in patients, as mentioned above for the treatment of melanoma patients with CTLA-4- and PD-1-specific antibodies. The optimization of such approaches demands a clearer understanding of how the various blocking antibodies really mediate their effects in vivo. One example is treatment with anti-CTLA-4 blocking antibodies, which impacts on "exhausted"/effector T cells and Tregs. Despite its profound effects in vivo, knowledge of the 
underlying mechanism is still limited. Interestingly, the mechanism of action of CTLA-4 blockade does not involve direct reprogramming of dysfunctional $\mathrm{T}$ cells [68-71]. A remarkable study compared transcriptomic data of $\mathrm{T}$ cells and monocytic cells obtained from patients before and after treatment with anti-CTLA-4, anti-PD-1, or concomitant treatment with both antibodies. It showed that the $\mathrm{T}$ cell transcriptomic changes observed after anti-PD1 treatment were associated with a NK cell signature, and with increased granzyme B expression. Intriguingly, the changes in T cells observed after anti-CTLA-4 treatment were different, showing a strong association with proliferation and, in particular, an increase in Ki67 expression. The combination of both antibodies had a synergistic effect on T cells, with increased granzyme B and Ki67 expression, as well as production of IFN $\gamma$ and IL-2 within TILs and PBMC of treated patients [72]. These complementary effects explain, at least in part, why combination therapy with these two antibodies is so powerful for the treatment of melanoma patients.

Unfortunately, translational studies have not confirmed previous animal studies which had indicated that CTLA-4 targeting can be used to treat various different cancers [73]. Why is CTLA-4 blockade only helpful for melanoma patients but not for patients with other cancers, whereas PD-1/PD-L1 blockade provides benefit for patients with several different types of cancer? This discrepancy recapitulates the idea that, whilst inhibitory receptors share functional principles, they have quite distinct modes of action (reviewed in [18,74-76]). Little is known as to whether some of these mechanisms may differ between humans and mice, and further human studies are required to improve our understanding. Nevertheless, we propose a more trivial explanation behind the unique success of CTLA-4 blockade in melanoma patients, as follows. In mice, the absence of CTLA-4 results in a lethal lymphoproliferative disease, revealing the extremely powerful role of this receptor [11,12]. Therefore, it is not surprising that CTLA-4 blockade can exhibit significant toxicity, and that it is not possible to fully block CTLA-4 in patients. Melanoma is highly immunogenic and the immune system has a higher potential to combat melanoma as compared to other cancers. This partial inhibition may be sufficient to achieve clinical benefit in melanoma patients. In contrast, blocking of PD-1/PD-ligand pathways is less toxic and can, therefore, be more strongly blocked, leading to more profound immune stimulation, and increasing the chance of mobilizing an effective $\mathrm{T}$ cell response in patients with various different cancers.

\section{Signaling and transcriptional regulation in "exhausted" T cells}

Novel therapeutic targets are likely to emerge from studies of cytoplasmic and nuclear proteins. Thorough transcriptomic studies of CD8 and CD4 T cells have been performed in models of chronic viral infection $[49,52,77,78]$ and compared to CD8 $\mathrm{T}$ cells obtained after acute infection. A similar study has also been carried out using tumor-specific CD8 T cells from cancer patients [54]. These studies have established that "exhaustion" is a differentiation state that clearly differs from other states of T cell dysfunction, such as anergy or senescence, although they share some characteristics (reviewed in [79]). For example, inhibitory receptors found on the surface of "exhausted" CD8 T cells may also be found on anergic T cells. Anergy is a well-defined state, induced by TCR triggering alone or ionomycin-triggered calcium flux [80,81]. In contrast, T cell "exhaustion" is likely more complex, involving many factors such as hypoxia, deprivation of essential amino acids, presence of inhibitory cytokines, engagement of inhibitory receptors and chronic stimulation of the TCR. Conceivably, aspects of the anergy-associated program are present in "exhausted" $\mathrm{T}$ cells, 
with many variations linked to other factors in the TME.

The transcriptomic studies mentioned above have shed light on some transcriptional regulators that could play major roles in the establishment and/or maintenance of $\mathrm{T}$ cell "exhaustion" (Figure 2). During chronic infection with LCMV clone 13 in mice, overexpression of the transcription factor BLIMP-1 was observed in "exhausted" CD8 T cells. Subsequent studies showed that moderate BLIMP-1 expression by CD8 T cells was actually necessary for optimal activation, whereas high expression levels inhibit CD8 T cell functions [82]. In CD8 T cells from HIV+ patients, as well as in CD8 T cells stimulated in the presence of PD-1 ligand, BATF (initially described as a negative regulator of the AP-1 transcription factor family) is highly expressed and participates in the dampening of cytokine production and proliferation [52]. Recently, it was elegantly shown that NFAT family members expressed in $\mathrm{T}$ cells are required for the expression of "exhaustion"-associated genes [83]. NFAT activation was shown to be at least partially induced in TILs, similar to what has been observed in anergic $\mathrm{T}$ cells.

Two members of the T-box family of transcription factors, Tbet (Tbx21) and Eomes, play a central role in the differentiation of CTLs and Th1 CD4 T cells [84-88]. The balanced expression of these transcription factors has also been shown to play a role in the regulation of "exhaustion". Higher expression of Eomes during chronic infection in mouse and human was associated with increased expression of inhibitory receptors, and a reduced capacity for cytokine production and proliferation $[89,90]$. On the other hand, the boosting of a tumorspecific $\mathrm{T}$ cell response following inhibitory receptor blockade correlated with higher expression of Tbet and IFN $\gamma$ production [91].

Even though antigen persistence and chronic stimulation of the TCR play dominant roles during chronic infection or in the TME, additional parameters must be taken into account. Hypoxia is likely involved. For instance, the Von-Hippel Lindau (VHL) tumor suppressor, an inhibitor of Hypoxia Induced Factor 1 alpha (HIF1 $\alpha$ ) was also shown to participate in the regulation of "exhaustion" in CD8 T cells [92]. The presence of inhibitory cytokines such as IL-10 and Transforming Growth Factor (TGF)- $\beta$ also influences $T$ cell differentiation in the TME and during chronic infection. TGF $\beta$ acts through the activation of the transcription factors Smad-2 and -3 . The transcription factor FOXP-1 was also shown to mediate suppressive effects of TGF $\beta$ on CD8 T cells, via inhibition of c-JUN, a member of the AP-1 transcription factor family. This effect was observed in ovarian cancer patients and in mouse models [93]. Indoleamine 2,3-dioxygenase (IDO) is an intracellular enzyme that degrades the essential amino acid 1-tryptophan into immunosuppressive metabolites along the kynurenine pathway [94]. IDO is produced by various cell types (tumor cells, plasmacytoid dendritic cells, monocytic myeloid-derived suppressor cells or mesenchymal stem cells) during cancer development. Tryptophan depletion and accumulation of these tryptophan derivatives can block antigen-specific $\mathrm{T}$ cell proliferation. IDO enzymatic activity activates the arylhydrocarbon receptor (AHR) [95-97]. Recent studies have shown that developmental activation of AHR leads to a long-lasting reduction in the response of CD8 $\mathrm{T}$ cells during influenza virus infection through alteration of DNA methylation and gene expression patterns which push CD8 T cells toward an "exhausted" transcriptomic program [98]. AHR and HIF1 $\alpha$ have also been shown to control type 1 regulatory T cell differentiation [99].

In a spontaneous (autochthonous) mouse melanoma model (TiRP mice [100,101]), we have shown that the up-regulation of A20 (tnfaip3), a ubiquitin transferase that is one of the major inhibitors of the NF- $\mathrm{BB}$ pathway, plays a major role in preventing an efficient CD8 $\mathrm{T}$ cell 
response against melanoma tumors [102]. Interestingly, A20-deficient CD8 T cells were able to boost tumor elimination, restoring cytokine production (IL-2 and IFN $\gamma$ ) and reducing PD-1 expression at the surface of tumor-specific CD8 T cells [102].

Attempts have been made to try to find new targets in the TME. Taking advantage of the thoroughly studied B16 melanoma model, a well designed shRNA screening led to the identification of the inhibitory role of the protein encoded by ppp $2 r 2 d$, a sub-unit of the PP2A phosphatase family [103]. This discovery is not surprising considering the well-described role of PP2A in inhibitory signaling in T cells. Similar approaches may be valuable for the discovery of additional genes and pathways involved in the regulation of T cell "exhaustion".

Altogether, it appears that TCR signaling in "exhausted" CD8 T cells drives the nuclear translocation of NFAT in T cells. The absence of co-stimulation, as well as the negative regulation of both $\mathrm{AP}-1$ and $\mathrm{NF}-\mathrm{\kappa B}$, likely impairs the full transcriptional program of activation, ultimately preventing the development of $\mathrm{CD} 8 \mathrm{~T}$ cell functions required for tumor rejection (Figure 2).

Despite these functional alterations and the attenuation of effector functions, it is important to note that "exhausted" $\mathrm{T}$ cells still have considerable potential to fight infectious or malignant disease. The elimination of "exhausted" $\mathrm{T}$ cells usually results in disease exacerbation, compatible with findings in animal models demonstrating that the transfer of "exhausted" $\mathrm{T}$ cells still confers protection from acute infection [104]. Therefore, the term "exhaustion" is somewhat misleading, because it gives the erroneous impression that these $\mathrm{T}$ cells have lost their protective capacity. In reality, $\mathrm{T}$ cells in chronic infection and cancer retain a high potential that can be mobilized by various therapeutic interventions. Complete exhaustion may occur only towards the end of a T cell's life-span. Nevertheless, in chronic infection and cancer, the majority of $\mathrm{T}$ cells have at least some functional capacity, indicating that they are functionally adapted to chronic antigen stimulation and inflammation, rather than truly exhausted [105]. In order to emphasize the importance of this residual functional potential in chronic disease, we propose that $\mathrm{T}$ cells may be evaluated with respect to an additional "correlate of protection", namely the resistance to immune inhibition and "exhaustion" (Figure 1). With increasing resistance to inhibition, as facilitated in the clinic by antibody blockade of inhibitory receptors, $\mathrm{T}$ cells become more successful in the fight against infection and cancer.

It is likely that $\mathrm{T}$ cells in chronic infection and cancer undergo a dedicated program of differentiation, and that this generates specialized populations for effector and memory functions, analogous to T cell differentiation in acute disease. Instead of "exhausted T cells" we therefore propose the terms "long-term effector T cells" and "memory-like T cells", which are more accurate terms for the effector and memory cells that combat long-term diseases [105]. Future research will allow a more precise understanding of the underlying mechanisms and cell differentiation, and will likely reveal further therapeutic opportunities. 


\section{Conclusions}

In this review, we intentionally emphasized the balance between $\mathrm{T}$ cells and clinical outcomes. It is certainly well known that many other biological mechanisms play major roles in cancer, as outlined by the other articles in this issue and the vast scientific literature. A thorough understanding of malignant diseases will depend on the integrated knowledge of these players and their numerous interactions between cancer and the host. A major reason why we position anti-cancer $\mathrm{T}$ cells very centrally is because they play central roles in the immune defense against cancer. Nevertheless, tumor rejection can only happen in the presence of several other factors that support these anti-cancer $\mathrm{T}$ cells and reduce their inhibition. A second reason why we outline their importance is because detailed knowledge of anti-cancer $\mathrm{T}$ cells of individual cancer patients provides us with valuable information about the degree to which the patient's immune defenses are mobilized against the disease. Therefore, we think that continued development of prognostic tools and therapy prediction in cancer will strongly depend on the systematic investigation of anti-cancer $\mathrm{T}$ cell responses.

In the past, many treatments for metastatic cancer arising from solid tissues have brought relatively moderate progress, often extending patient survival by only a few weeks or months. This notion does not, of course, apply to the considerable number of highly efficient interventions, such as early complete surgical removal, or chemotherapy for selected cancers, which often provide long-term cure. Nevertheless, the frequent and metastatic cancers arising from organs such as lung, colon, pancreas, kidney, breast or prostate remain the "big killers", against which current treatments provide only relatively short patient survival benefit, despite recent major advances provided by targeted therapies such as tyrosine kinase inhibitors (Figure 3, "Current tumor targeted therapy"). In contrast, novel data [17] demonstrates that the vast majority of melanoma patients who were alive 2-3 years after receiving immunotherapy with Ipilimumab continued to do well for at least 12 years (Figure 3, "Current immunotherapy"), reminiscent of the long-term benefit provided by the graft-versus-leukemia effect. It seems likely that further development in immunotherapy will bring progress not only in extension of patient survival, but also in the proportion of cured patients. 


\section{Conflict of interest}

The authors declare that they have no conflict of interest related to this work.

\section{Acknowledgements and support}

We are grateful to patients and colleagues for their dedicated collaboration and support. We apologize for not mentioning and citing numerous studies due to space limitations. This work was supported by the Cancer Research Institute (USA), Ludwig Cancer Research (USA), the Cancer Vaccine Collaborative (USA), Atlantic Philanthropies (USA), the Wilhelm SanderFoundation (Germany), and grants from the Polish-Swiss collaboration support (PSPB 070/210), Swiss Cancer Research (3507-08-2014), Swiss National Science Foundation (CRSII3_141879), and SwissTransMed (KIP 18). 


\section{References}

[1] D.T. Fearon, P. Manders, S.D. Wagner, Arrested differentiation, the self-renewing memory lymphocyte, and vaccination, Science (New York, NY). 293 (2001) 248-250. doi:10.1126/science.1062589.

[2] M. Zanetti, S.P. Schoenberger, Memory T Cells. Preface, Adv. Exp. Med. Biol. 684 (2010) vii-ix.

[3] N. Zhang, M.J. Bevan, CD8(+) T cells: foot soldiers of the immune system, Immunity. 35 (2011) 161-168. doi:10.1016/j.immuni.2011.07.010.

[4] L. Gattinoni, C.A. Klebanoff, N.P. Restifo, Paths to stemness: building the ultimate antitumour T cell, Nat Rev Cancer. 12 (2012) 671-684. doi:10.1038/nrc3322.

[5] P. Graef, V.R. Buchholz, C. Stemberger, M. Flossdorf, L. Henkel, M. Schiemann, et al., Serial transfer of single-cell-derived immunocompetence reveals stemness of CD8(+) central memory T cells, Immunity. 41 (2014) 116-126. doi:10.1016/j.immuni.2014.05.018.

[6] S.A. Fuertes Marraco, C. Soneson, L. Cagnon, P.O. Gannon, M. Allard, S.A. Maillard, et al., Long-lasting stem cell-like memory CD8+ T cells with a naïve-like profile upon yellow fever vaccination, Sci Transl Med. 7 (2015) 282ra48. doi:10.1126/scitranslmed.aaa3700.

[7] D.W. MD, Best Practice \& Research Clinical Haematology, Best Practice \& Research Clinical Haematology. 26 (2013) 293-296. doi:10.1016/j.beha.2013.10.010.

[8] P. Vyas, F.R. Appelbaum, C. Craddock, Biology of Blood and Marrow Transplantation, Biology of Blood and Marrow Transplantation. 21 (2015) 8-15. doi:10.1016/j.bbmt.2014.10.026.

[9] T.L. Walunas, D.J. Lenschow, C.Y. Bakker, P.S. Linsley, G.J. Freeman, J.M. Green, et al., CTLA-4 can function as a negative regulator of T cell activation, Immunity. 1 (1994) 405413.

[10] M.F. Krummel, J.P. Allison, CD28 and CTLA-4 have opposing effects on the response of T cells to stimulation, J Exp Med. 182 (1995) 459-465.

[11] P. Waterhouse, J.M. Penninger, E. Timms, A. Wakeham, A. Shahinian, K.P. Lee, et al., Lymphoproliferative disorders with early lethality in mice deficient in Ctla-4, Science (New York, NY). 270 (1995) 985-988.

[12] E.A. Tivol, F. Borriello, A.N. Schweitzer, W.P. Lynch, J.A. Bluestone, A.H. Sharpe, Loss of CTLA-4 leads to massive lymphoproliferation and fatal multiorgan tissue destruction, revealing a critical negative regulatory role of CTLA-4, Immunity. 3 (1995) 541-547.

[13] D.R. Leach, M.F. Krummel, J.P. Allison, Enhancement of antitumor immunity by CTLA-4 blockade, Science (New York, NY). 271 (1996) 1734-1736.

[14] M.K. Callahan, J.D. Wolchok, At the bedside: CTLA-4- and PD-1-blocking antibodies in cancer immunotherapy, J Leukoc Biol. 94 (2013) 41-53. doi:10.1189/jlb.1212631.

[15] F.S. Hodi, S.J. O'Day, D.F. McDermott, R.W. Weber, J.A. Sosman, J.B. Haanen, et al., Improved survival with ipilimumab in patients with metastatic melanoma, N Engl J Med. 363 (2010) 711-723. doi:10.1056/NEJMoa1003466.

[16] C. Robert, L. Thomas, I. Bondarenko, S. O'Day, J. Weber, C. Garbe, et al., Ipilimumab plus Dacarbazine for Previously Untreated Metastatic Melanoma, N Engl J Med. 364 (2011) 2517-2526. doi:10.1056/NEJMoa1104621.

[17] D. Schadendorf, F.S. Hodi, C. Robert, J.S. Weber, K. Margolin, O. Hamid, et al., Pooled Analysis of Long-Term Survival Data From Phase II and Phase III Trials of Ipilimumab in Unresectable or Metastatic Melanoma, Journal of Clinical Oncology. (2015). doi:10.1200/JCO.2014.56.2736.

[18] M.E. Keir, M.J. Butte, G.J. Freeman, A.H. Sharpe, PD-1 and its ligands in tolerance and immunity, Annu Rev Immunol. 26 (2008) 677-704. doi:10.1146/annurev.immunol.26.021607.090331.

[19] J.M. Taube, R.A. Anders, G.D. Young, H. Xu, R. Sharma, T.L. McMiller, et al., 
Colocalization of inflammatory response with B7-h1 expression in human melanocytic lesions supports an adaptive resistance mechanism of immune escape, Sci Transl Med. 4 (2012) 127ra37. doi:10.1126/scitranslmed.3003689.

[20] Y. Iwai, M. Ishida, Y. Tanaka, T. Okazaki, T. Honjo, N. Minato, Involvement of PD-L1 on tumor cells in the escape from host immune system and tumor immunotherapy by PD-L1 blockade, Proc Natl Acad Sci USA. 99 (2002) 12293-12297. doi:10.1073/pnas.192461099.

[21] H. Dong, S.E. Strome, D.R. Salomao, H. Tamura, F. Hirano, D.B. Flies, et al., Tumorassociated B7-H1 promotes T-cell apoptosis: a potential mechanism of immune evasion, Nat Med. 8 (2002) 793-800. doi:10.1038/nm730.

[22] C. Robert, J. Schachter, G.V. Long, A. Arance, J.-J. Grob, L. Mortier, et al., Pembrolizumab versus Ipilimumab in Advanced Melanoma, N Engl J Med. (2015). doi:10.1056/NEJMoa1503093.

[23] S.L. Topalian, F.S. Hodi, J.R. Brahmer, S.N. Gettinger, D.C. Smith, D.F. McDermott, et al., Safety, activity, and immune correlates of anti-PD-1 antibody in cancer, N Engl J Med. 366 (2012) 2443-2454. doi:10.1056/NEJMoa1200690.

[24] E.B. Garon, N.A. Rizvi, R. Hui, N. Leighl, A.S. Balmanoukian, J.P. Eder, et al., Pembrolizumab for the Treatment of Non-Small-Cell Lung Cancer, N Engl J Med. (2015). doi:10.1056/NEJMoa1501824.

[25] M.K. Callahan, M.A. Postow, J.D. Wolchok, CTLA-4 and PD-1 Pathway Blockade: Combinations in the Clinic, Frontiers in Oncology. 4 (2014) 385. doi:10.3389/fonc.2014.00385.

[26] J. Naidoo, D.B. Page, J.D. Wolchok, Immune modulation for cancer therapy, British Journal of Cancer. (2014). doi:10.1038/bjc.2014.348.

[27] D.S. Shin, A. Ribas, The evolution of checkpoint blockade as a cancer therapy: what's here, what's next? Curr Opin Immunol. 33 (2015) 23-35. doi:10.1016/j.coi.2015.01.006.

[28] J.D. Wolchok, H. Kluger, M.K. Callahan, M.A. Postow, N.A. Rizvi, A.M. Lesokhin, et al., Nivolumab plus ipilimumab in advanced melanoma, N Engl J Med. 369 (2013) 122-133. doi:10.1056/NEJMoa1302369.

[29] D.E. Speiser, D. Lienard, M.J. Pittet, P. Batard, D. Rimoldi, P. Guillaume, et al., In vivo activation of melanoma-specific CD8(+) T cells by endogenous tumor antigen and peptide vaccines. A comparison to virus-specific T cells, Eur. J. Immunol. 32 (2002) 731-741. doi:10.1002/1521-4141(200203)32:3\&\#60;731::AID-IMMU731\&\#62;3.0.CO;2-H.

[30] J.B.A.G. Haanen, A. Baars, R. Gomez, P. Weder, M. Smits, T.D. de Gruijl, et al., Melanoma-specific tumor-infiltrating lymphocytes but not circulating melanoma-specific $\mathrm{T}$ cells may predict survival in resected advanced-stage melanoma patients, Cancer Immunol Immunother. 55 (2006) 451-458. doi:10.1007/s00262-005-0018-5.

[31] W.-H. Fridman, F. Pagès, C. Sautes-Fridman, J. Galon, The immune contexture in human tumours: impact on clinical outcome, Nat Rev Cancer. 12 (2012) 298-306. doi:10.1038/nrc3245.

[32] M. Gerlinger, A.J. Rowan, S. Horswell, J. Larkin, D. Endesfelder, E. Gronroos, et al., Intratumor heterogeneity and branched evolution revealed by multiregion sequencing, $\mathrm{N}$ Engl J Med. 366 (2012) 883-892. doi:10.1056/NEJMoa1113205.

[33] E. Romano, S. Pradervand, A. Paillusson, J. Weber, K. Harshman, K. Muehlethaler, et al., Identification of multiple mechanisms of resistance to Vemurafenib in a patient with BRAFV600E-mutated cutaneous melanoma successfully rechallenged after progression, Clin Cancer Res. 19 (2013) 5749-5757. doi:10.1158/1078-0432.CCR-13-0661.

[34] T.N. Schumacher, R.D. Schreiber, Neoantigens in cancer immunotherapy, Science (New York, NY). 348 (2015) 69-74. doi:10.1126/science.aaa4971.

[35] M.M. Gubin, X. Zhang, H. Schuster, E. Caron, J.P. Ward, T. Noguchi, et al., Checkpoint blockade cancer immunotherapy targets tumour-specific mutant antigens, Nature. 515 (2014) 577-581. doi:10.1038/nature13988.

[36] M. Yadav, S. Jhunjhunwala, Q.T. Phung, P. Lupardus, J. Tanguay, S. Bumbaca, et al., Predicting immunogenic tumour mutations by combining mass spectrometry and exome sequencing, Nature. 515 (2014) 572-576. doi:10.1038/nature14001.

[37] R.S. Herbst, J.-C. Soria, M. Kowanetz, G.D. Fine, O. Hamid, M.S. Gordon, et al., 
Predictive correlates of response to the anti-PD-L1 antibody MPDL3280A in cancer patients, Nature. 515 (2014) 563-567. doi:10.1038/nature14011.

[38] C. Linnemann, M.M. van Buuren, L. Bies, E.M.E. Verdegaal, R. Schotte, J.J.A. Calis, et al., High-throughput epitope discovery reveals frequent recognition of neo-antigens by CD4+ T cells in human melanoma, Nat Med. 21 (2015) 81-85. doi:10.1038/nm.3773.

[39] N.A. Rizvi, M.D. Hellmann, A. Snyder, P. Kvistborg, V. Makarov, J.J. Havel, et al., Cancer immunology. Mutational landscape determines sensitivity to PD-1 blockade in non-small cell lung cancer, Science (New York, NY). 348 (2015) 124-128. doi:10.1126/science.aaa1348.

[40] L. Baitsch, S.A. Fuertes Marraco, A. Legat, C. Meyer, D.E. Speiser, The three main stumbling blocks for anticancer T cells, Trends Immunol. 33 (2012) 364-372. doi:10.1016/j.it.2012.02.006.

[41] P. Allavena, A. Mantovani, Immunology in the clinic review series; focus on cancer: tumour-associated macrophages: undisputed stars of the inflammatory tumour microenvironment, Clin. Exp. Immunol. 167 (2012) 195-205. doi:10.1111/j.13652249.2011.04515.x.

[42] D.I. Gabrilovich, S. Ostrand-Rosenberg, V. Bronte, Coordinated regulation of myeloid cells by tumours, Nat Rev Immunol. 12 (2012) 253-268. doi:10.1038/nri3175.

[43] C. Devaud, L.B. John, J.A. Westwood, P.K. Darcy, M.H. Kershaw, Immune modulation of the tumor microenvironment for enhancing cancer immunotherapy, OncoImmunology. 2 (2013) e25961. doi:10.4161/onci.25961.

[44] M.A. Swartz, Immunomodulatory Roles of Lymphatic Vessels in Cancer Progression, Cancer Immunology Research. 2 (2014) 701-707. doi:10.1158/2326-6066.CIR-14-0115.

[45] D.A.A. Vignali, L.W. Collison, C.J. Workman, How regulatory T cells work, Nat Rev Immunol. 8 (2008) 523-532. doi:10.1038/nri2343.

[46] S. Ostrand-Rosenberg, P. Sinha, Myeloid-derived suppressor cells: linking inflammation and cancer, J Immunol. 182 (2009) 4499-4506. doi:10.4049/jimmunol.0802740.

[47] A. Ostman, M. Augsten, Cancer-associated fibroblasts and tumor growth--bystanders turning into key players, Curr. Opin. Genet. Dev. 19 (2009) 67-73. doi:10.1016/j.gde.2009.01.003.

[48] S.D. Blackburn, H. Shin, W.N. Haining, T. Zou, C.J. Workman, A. Polley, et al., Coregulation of CD8+ T cell exhaustion by multiple inhibitory receptors during chronic viral infection, Nat Immunol. 10 (2009) 29-37. doi:10.1038/ni.1679.

[49] E.J. Wherry, S.-J. Ha, S.M. Kaech, W.N. Haining, S. Sarkar, V. Kalia, et al., Molecular signature of CD8+ T cell exhaustion during chronic viral infection, Immunity. 27 (2007) 670-684. doi:10.1016/j.immuni.2007.09.006.

[50] E.J. Wherry, D.L. Barber, S.M. Kaech, J.N. Blattman, R. Ahmed, Antigen-independent memory CD8 T cells do not develop during chronic viral infection, Proc Natl Acad Sci USA. 101 (2004) 16004-16009. doi:10.1073/pnas.0407192101.

[51] C.L. Day, D.E. Kaufmann, P. Kiepiela, J.A. Brown, E.S. Moodley, S. Reddy, et al., PD-1 expression on HIV-specific T cells is associated with T-cell exhaustion and disease progression, Nature. 443 (2006) 350-354. doi:10.1038/nature05115.

[52] M. Quigley, F. Pereyra, B. Nilsson, F. Porichis, C. Fonseca, Q. Eichbaum, et al., Transcriptional analysis of HIV-specific CD8+ T cells shows that PD-1 inhibits T cell function by upregulating BATF, Nat Med. 16 (2010) 1147-1151. doi:10.1038/nm.2232.

[53] M. Larsson, E.M. Shankar, K.F. Che, A. Saeidi, R. Ellegård, M. Barathan, et al., Molecular signatures of T-cell inhibition in HIV-1 infection, Retrovirology. 10 (2013) 31. doi:10.1186/1742-4690-10-31.

[54] L. Baitsch, P. Baumgaertner, E. Devêvre, S.K. Raghav, A. Legat, L. Barba, et al., Exhaustion of tumor-specific CD8+ T cells in metastases from melanoma patients, J Clin Invest. 121 (2011) 2350-2360. doi:10.1172/JCI46102.

[55] J. Fourcade, Z. Sun, O. Pagliano, P. Guillaume, I.F. Luescher, C. Sander, et al., CD8(+) T cells specific for tumor antigens can be rendered dysfunctional by the tumor microenvironment through upregulation of the inhibitory receptors BTLA and PD-1, Cancer Res. 72 (2012) 887-896. doi:10.1158/0008-5472.CAN-11-2637. 
[56] A. Zippelius, P. Batard, V. Rubio-Godoy, G. Bioley, D. Lienard, F. Lejeune, et al., Effector function of human tumor-specific CD8 T cells in melanoma lesions: a state of local functional tolerance, Cancer Res. 64 (2004) 2865-2873.

[57] A. Legat, D.E. Speiser, H. Pircher, D. Zehn, S.A. Fuertes Marraco, Inhibitory Receptor Expression Depends More Dominantly on Differentiation and Activation than "Exhaustion" of Human CD8 T Cells, Frontiers in Immunology. 4 (2013) 455. doi:10.3389/fimmu.2013.00455.

[58] L.G. Radvanyi, C. Bernatchez, M. Zhang, P.S. Fox, P. Miller, J. Chacon, et al., Specific Lymphocyte Subsets Predict Response to Adoptive Cell Therapy Using Expanded Autologous Tumor-Infiltrating Lymphocytes in Metastatic Melanoma Patients, Clinical Cancer Research. 18 (2012) 6758-6770. doi:10.1158/1078-0432.CCR-12-1177.

[59] A. Gros, P.F. Robbins, X. Yao, Y.F. Li, S. Turcotte, E. Tran, et al., PD-1 identifies the patient-specific CD8+ tumor-reactive repertoire infiltrating human tumors, J Clin Invest. 124 (2014) 2246-2259. doi:10.1172/JCI73639DS1.

[60] T. Pentcheva-Hoang, J.G. Egen, K. Wojnoonski, J.P. Allison, B7-1 and B7-2 selectively recruit CTLA-4 and CD28 to the immunological synapse, Immunity. 21 (2004) 401-413. doi:10.1016/j.immuni.2004.06.017.

[61] C.J. Nirschl, C.G. Drake, Molecular pathways: coexpression of immune checkpoint molecules: signaling pathways and implications for cancer immunotherapy, Clin Cancer Res. 19 (2013) 4917-4924. doi:10.1158/1078-0432.CCR-12-1972.

[62] M. Rangachari, C. Zhu, K. Sakuishi, S. Xiao, J. Karman, A. Chen, et al., Bat3 promotes T cell responses and autoimmunity by repressing Tim-3-mediated cell death and exhaustion, Nat Med. 18 (2012) 1394-1400. doi:10.1038/nm.2871.

[63] Y.-H. Huang, C. Zhu, Y. Kondo, A.C. Anderson, A. Gandhi, A. Russell, et al., CEACAM1 regulates TIM-3-mediated tolerance and exhaustion, Nature. 517 (2015) 386-390. doi:10.1038/nature13848.

[64] L. Derré, J.-P. Rivals, C. Jandus, S. Pastor, D. Rimoldi, P. Romero, et al., BTLA mediates inhibition of human tumor-specific CD8+ T cells that can be partially reversed by vaccination, J Clin Invest. 120 (2010) 157-167. doi:10.1172/JCI40070.

[65] R.J. Johnston, L. Comps-Agrar, J. Hackney, X. Yu, M. Huseni, Y. Yang, et al., The immunoreceptor TIGIT regulates antitumor and antiviral CD8(+) T cell effector function, Cancer Cell. 26 (2014) 923-937. doi:10.1016/j.ccell.2014.10.018.

[66] X. Yu, K. Harden, L. C Gonzalez, M. Francesco, E. Chiang, B. Irving, et al., The surface protein TIGIT suppresses $\mathrm{T}$ cell activation by promoting the generation of mature immunoregulatory dendritic cells, Nat Immunol. 10 (2008) 48-57. doi:10.1038/ni.1674.

[67] C.J. Workman, K.J. Dugger, D.A.A. Vignali, Cutting edge: molecular analysis of the negative regulatory function of lymphocyte activation gene-3, J Immunol. 169 (2002) 5392-5395.

[68] K.S. Peggs, S.A. Quezada, C.A. Chambers, A.J. Korman, J.P. Allison, Blockade of CTLA4 on both effector and regulatory $\mathrm{T}$ cell compartments contributes to the antitumor activity of anti-CTLA-4 antibodies, Journal of Experimental Medicine. 206 (2009) 1717-1725. doi:10.1084/jem.20082492.

[69] T. Takahashi, T. Tagami, S. Yamazaki, T. Uede, J. Shimizu, N. Sakaguchi, et al., Immunologic self-tolerance maintained by $\mathrm{CD} 25(+) \mathrm{CD} 4(+)$ regulatory $\mathrm{T}$ cells constitutively expressing cytotoxic T lymphocyte-associated antigen 4, J Exp Med. 192 (2000) 303-310.

[70] S. Read, V. Malmström, F. Powrie, Cytotoxic T lymphocyte-associated antigen 4 plays an essential role in the function of $\mathrm{CD} 25(+) \mathrm{CD} 4(+)$ regulatory cells that control intestinal inflammation, J Exp Med. 192 (2000) 295-302.

[71] L.S.K. Walker, D.M. Sansom, The emerging role of CTLA4 as a cell-extrinsic regulator of T cell responses, Nat Rev Immunol. 11 (2011) 852-863. doi:10.1038/nri3108.

[72] R. Das, R. Verma, M. Sznol, C.S. Boddupalli, S.N. Gettinger, H. Kluger, et al., Combination therapy with anti-CTLA-4 and anti-PD-1 leads to distinct immunologic changes in vivo, The Journal of Immunology. 194 (2015) 950-959.

doi:10.4049/jimmunol.1401686. 
[73] J.F. Grosso, M.N. Jure-Kunkel, CTLA-4 blockade in tumor models: an overview of preclinical and translational research, Cancer Immun. 13 (2013) 5.

[74] E.J. Vazquez-Cintron, N.R. Monu, A.B. Frey, Tumor-Induced Disruption of Proximal TCR-Mediated Signal Transduction in Tumor-Infiltrating CD8+ Lymphocytes Inactivates Antitumor Effector Phase, The Journal of Immunology. 185 (2010) 7133-7140. doi:10.4049/jimmunol.1001157.

[75] C. Kyi, M.A. Postow, Checkpoint blocking antibodies in cancer immunotherapy, FEBS Lett. 588 (2013) 368-376. doi:10.1016/j.febslet.2013.10.015.

[76] L.T. Nguyen, P.S. Ohashi, Clinical blockade of PD1 and LAG3--potential mechanisms of action, Nat Rev Immunol. 15 (2015) 45-56. doi:10.1038/nri3790.

[77] T.A. Doering, A. Crawford, J.M. Angelosanto, M.A. Paley, C.G. Ziegler, E.J. Wherry, Network Analysis Reveals Centrally Connected Genes and Pathways Involved in CD8, Immunity. 37 (2012) 1130-1144. doi:10.1016/j.immuni.2012.08.021.

[78] A. Crawford, J.M. Angelosanto, C. Kao, T.A. Doering, P.M. Odorizzi, B.E. Barnett, et al., Molecular and transcriptional basis of CD4+ T cell dysfunction during chronic infection, Immunity. 40 (2014) 289-302. doi:10.1016/j.immuni.2014.01.005.

[79] J. Crespo, H. Sun, T.H. Welling, Z. Tian, W. Zou, T cell anergy, exhaustion, senescence, and stemness in the tumor microenvironment, Curr Opin Immunol. 25 (2013) 214-221. doi:10.1016/j.coi.2012.12.003.

[80] I.A. Parish, S. Rao, G.K. Smyth, T. Juelich, G.S. Denyer, G.M. Davey, et al., The molecular signature of CD8+ T cells undergoing deletional tolerance, Blood. 113 (2009) 4575-4585. doi:10.1182/blood-2008-10-185223.

[81] F. Macián, F. García-Cózar, S.-H. Im, H.F. Horton, M.C. Byrne, A. Rao, Transcriptional mechanisms underlying lymphocyte tolerance, Cell. 109 (2002) 719-731.

[82] H. Shin, S.D. Blackburn, A.M. Intlekofer, C. Kao, J.M. Angelosanto, S.L. Reiner, et al., A role for the transcriptional repressor Blimp-1 in CD8(+) T cell exhaustion during chronic viral infection, Immunity. 31 (2009) 309-320. doi:10.1016/j.immuni.2009.06.019.

[83] G.J. Martinez, R.M. Pereira, T. Äijö, E.Y. Kim, F. Marangoni, M.E. Pipkin, et al., The Transcription Factor NFAT Promotes Exhaustion of Activated CD8, Immunity. 42 (2015) 265-278. doi:10.1016/j.immuni.2015.01.006.

[84] A.M. Intlekofer, N. Takemoto, E.J. Wherry, S.A. Longworth, J.T. Northrup, V.R. Palanivel, et al., Effector and memory CD8+ T cell fate coupled by T-bet and eomesodermin, Nat Immunol. 6 (2005) 1236-1244. doi:10.1038/ni1268.

[85] J.M. Angelosanto, E.J. Wherry, Transcription factor regulation of CD8+ T-cell memory and exhaustion, Immunological Reviews. 236 (2010) 167-175. doi:10.1111/j.1600065X.2010.00927.x.

[86] J.A. Best, D.A. Blair, J. Knell, E. Yang, V. Mayya, A. Doedens, et al., Transcriptional insights into the CD8+ T cell response to infection and memory $\mathrm{T}$ cell formation, Nat Immunol. 14 (2013) 404-412. doi:10.1038/ni.2536.

[87] M. Grange, G. Verdeil, F. Arnoux, A. Griffon, S. Spicuglia, J. Maurizio, et al., Active STAT5 regulates T-bet and eomesodermin expression in CD8 T cells and imprints a T-betdependent Tc1 program with repressed IL-6/TGF- $\beta 1$ signaling, The Journal of Immunology. 191 (2013) 3712-3724. doi:10.4049/jimmunol.1300319.

[88] M.A. Curran, T.L. Geiger, W. Montalvo, M. Kim, S.L. Reiner, A. Al-Shamkhani, et al., Systemic 4-1BB activation induces a novel T cell phenotype driven by high expression of Eomesodermin, Journal of Experimental Medicine. 210 (2013) 743-755. doi:10.1084/jem.20121190.

[89] M.A. Paley, D.C. Kroy, P.M. Odorizzi, J.B. Johnnidis, D.V. Dolfi, B.E. Barnett, et al., Progenitor and terminal subsets of CD8+ T cells cooperate to contain chronic viral infection, Science (New York, NY). 338 (2012) 1220-1225. doi:10.1126/science.1229620.

[90] M. Buggert, J. Tauriainen, T. Yamamoto, J. Frederiksen, M.A. Ivarsson, J. Michaëlsson, et al., T-bet and Eomes Are Differentially Linked to the Exhausted Phenotype of CD8+ T Cells in HIV Infection, PLoS Pathog. 10 (2014) e1004251.

doi:10.1371/journal.ppat.1004251.s008.

[91] M.M. Berrien-Elliott, J. Yuan, L.E. Swier, S.R. Jackson, C.L. Chen, M.J. Donlin, et al., 
Checkpoint blockade immunotherapy relies on T-bet but not Eomes to induce effector function in tumor-infiltrating CD8+ T cells, Cancer Immunology Research. 3 (2015) 116124. doi:10.1158/2326-6066.CIR-14-0159.

[92] A.L. Doedens, A.T. Phan, M.H. Stradner, J.K. Fujimoto, J.V. Nguyen, E. Yang, et al., Hypoxia-inducible factors enhance the effector responses of CD8(+) T cells to persistent antigen, Nat Immunol. 14 (2013) 1173-1182. doi:10.1038/ni.2714.

[93] T.L. Stephen, M.R. Rutkowski, M.J. Allegrezza, A. Perales-Puchalt, A.J. Tesone, N. Svoronos, et al., Transforming Growth Factor beta-Mediated Suppression of Antitumor T Cells Requires FoxP1 Transcription Factor Expression, Immunity. 41 (2014) 427-439. doi:10.1016/j.immuni.2014.08.012.

[94] C. Uyttenhove, L. Pilotte, I. Théate, V. Stroobant, D. Colau, N. Parmentier, et al., Evidence for a tumoral immune resistance mechanism based on tryptophan degradation by indoleamine 2,3-dioxygenase, Nat Med. 9 (2003) 1269-1274. doi:10.1038/nm934.

[95] G. Frumento, R. Rotondo, M. Tonetti, G. Damonte, U. Benatti, G.B. Ferrara, Tryptophanderived catabolites are responsible for inhibition of $\mathrm{T}$ and natural killer cell proliferation induced by indoleamine 2,3-dioxygenase, J Exp Med. 196 (2002) 459-468.

[96] C.A. Opitz, U.M. Litzenburger, F. Sahm, M. Ott, I. Tritschler, S. Trump, et al., An endogenous tumour-promoting ligand of the human aryl hydrocarbon receptor, Nature. 478 (2011) 197-203. doi:10.1038/nature10491.

[97] W. Ling, J. Zhang, Z. Yuan, G. Ren, L. Zhang, X. Chen, et al., Mesenchymal stem cells use IDO to regulate immunity in tumor microenvironment, Cancer Res. 74 (2014) 1576-1587. doi:10.1158/0008-5472.CAN-13-1656.

[98] B. Winans, A. Nagari, M. Chae, C.M. Post, C.-I. Ko, A. Puga, et al., Linking the Aryl Hydrocarbon Receptor with Altered DNA Methylation Patterns and Developmentally Induced Aberrant Antiviral CD8+ T Cell Responses, The Journal of Immunology. 194 (2015) 4446-4457. doi:10.4049/jimmunol.1402044.

[99] I.D. Mascanfroni, M.C. Takenaka, A. Yeste, B. Patel, Y. Wu, J.E. Kenison, et al., Metabolic control of type 1 regulatory T cell differentiation by AHR and HIF1 $\alpha$, Nat Med. (2015). doi:10.1038/nm.3868.

[100] I.J. Huijbers, P. Krimpenfort, P. Chomez, M.A. van der Valk, J.-Y. Song, E.-M. InderbergSuso, et al., An inducible mouse model of melanoma expressing a defined tumor antigen, Cancer Res. 66 (2006) 3278-3286. doi:10.1158/0008-5472.CAN-05-3216.

[101] S.M. Soudja, M. Wehbe, A. Mas, L. Chasson, C.P. de Tenbossche, I. Huijbers, et al., Tumor-initiated inflammation overrides protective adaptive immunity in an induced melanoma model in mice, Cancer Res. 70 (2010) 3515-3525. doi:10.1158/00085472.CAN-09-4354.

[102] M. Giordano, R. Roncagalli, P. Bourdely, L. Chasson, M. Buferne, S. Yamasaki, et al., The tumor necrosis factor alpha-induced protein 3 (TNFAIP3, A20) imposes a brake on antitumor activity of CD8 T cells, Proc Natl Acad Sci USA. 111 (2014) 11115-11120. doi:10.1073/pnas.1406259111.

[103] P. Zhou, D.R. Shaffer, D.A. Alvarez Arias, Y. Nakazaki, W. Pos, A.J. Torres, et al., In vivo discovery of immunotherapy targets in the tumour microenvironment, Nature. 506 (2014) 52-57. doi:10.1038/nature12988.

[104] D.T. Utzschneider, A. Legat, S.A. Fuertes Marraco, L. Carrie, I. Luescher, D.E. Speiser, et al., T cells maintain an exhausted phenotype after antigen withdrawal and population reexpansion, Nat Immunol. 14 (2013) 603-610. doi:10.1038/ni.2606.

[105] D.E. Speiser, D.T. Utzschneider, S.G. Oberle, C. Münz, P. Romero, D. Zehn, T cell differentiation in chronic infection and cancer: functional adaptation or exhaustion? Nat Rev Immunol. 14 (2014) 768-774. doi:10.1038/nri3740.

[106] L. Galluzzi, E. Vacchelli, J.-M. Bravo-San Pedro, A. Buqué, L. Senovilla, E.E. Baracco, et al., Classification of current anticancer immunotherapies, Oncotarget. 5 (2014) 1247212508 . 


\section{Figure legends}

\section{Figure 1}

Properties of $\mathbf{T}$ cells that correlate with protection from disease ("correlates of protection"). In intracellular infections and in cancer, T cells can eliminate "diseased" cells and are thus central players in mediating immune protection. Unfortunately, $\mathrm{T}$ cell responses are often too weak or inadequate to be protective. Detailed analyses of $\mathrm{T}$ cells from experimental animal models and from patients are helpful in distinguishing protective from non-protective $\mathrm{T}$ cell responses. It is likely that all of the suggested correlates are required for protection. Further studies and improved techniques will refine these concepts and will continuously improve insights into relevant immune mechanisms.

\section{Figure 2}

Molecular regulation of "exhaustion" in CD8 $\mathbf{T}$ cells. Attenuation of T cell function is mediated at multiple levels. Several transcription factors have been shown to establish/maintain T cell "exhaustion" in tumor infiltrating lymphocytes (TILs; blue) or during chronic infections (green), or in both (blue and green). Surface inhibitory receptors (TIGIT, PD-1, LAG-3, TIM-3/CEACAM-1, BTLA, CD160) underlie important mechanisms that prevent efficient signaling from activatory receptors. Inhibitory receptors may interfere with activatory receptor-ligand interactions at the cell surface (not shown) or mediate their inhibitory effects via the recruitment of phosphatases (red) like SHP-1, SHP-2 or PP2A that dampen effective signaling downstream of the activatory pathways triggered by the TCR/CD3 complex, as well as cytokine and co-stimulatory receptors. Other inhibitory molecules like A20 (orange) participate in the shutdown of more specific signaling pathways. Additional signals from the microenvironment are integrated by the $\mathrm{T}$ cell, leading to further transcriptomic regulations. These various mechanisms prevent the development of an effective $\mathrm{T}$ cell response. IDO, indolamine 2,3-dioxygenase; TGF $\beta$, transforming growth factor-beta; havcr2, the gene that encodes TIM-3.

\section{Figure 3}

Immunotherapy increases the likelihood of clinical benefit by extending the fraction of patients that are cured. A major aim for future therapies is to fully cure cancer patients. In contrast to most other therapies for advanced metastatic cancers arising from solid tissues, immunotherapy has the potential to extend patient survival for many years, illustrated by a rise of the tail end of the survival curve. Note that immunological mechanisms are also part of many therapies that are classically not considered as immunotherapy [106]. The underlying mechanisms that support this rise are still only partially understood, calling for more in-depth analyses to identify which patients will benefit most from a particular treatment. Arrows suggest the potential progress provided by future therapies. Horizontal arrow: future prolongation of patient's survival for a few weeks/months; vertical arrow: future increase in percentages of patients with long-term survival. 


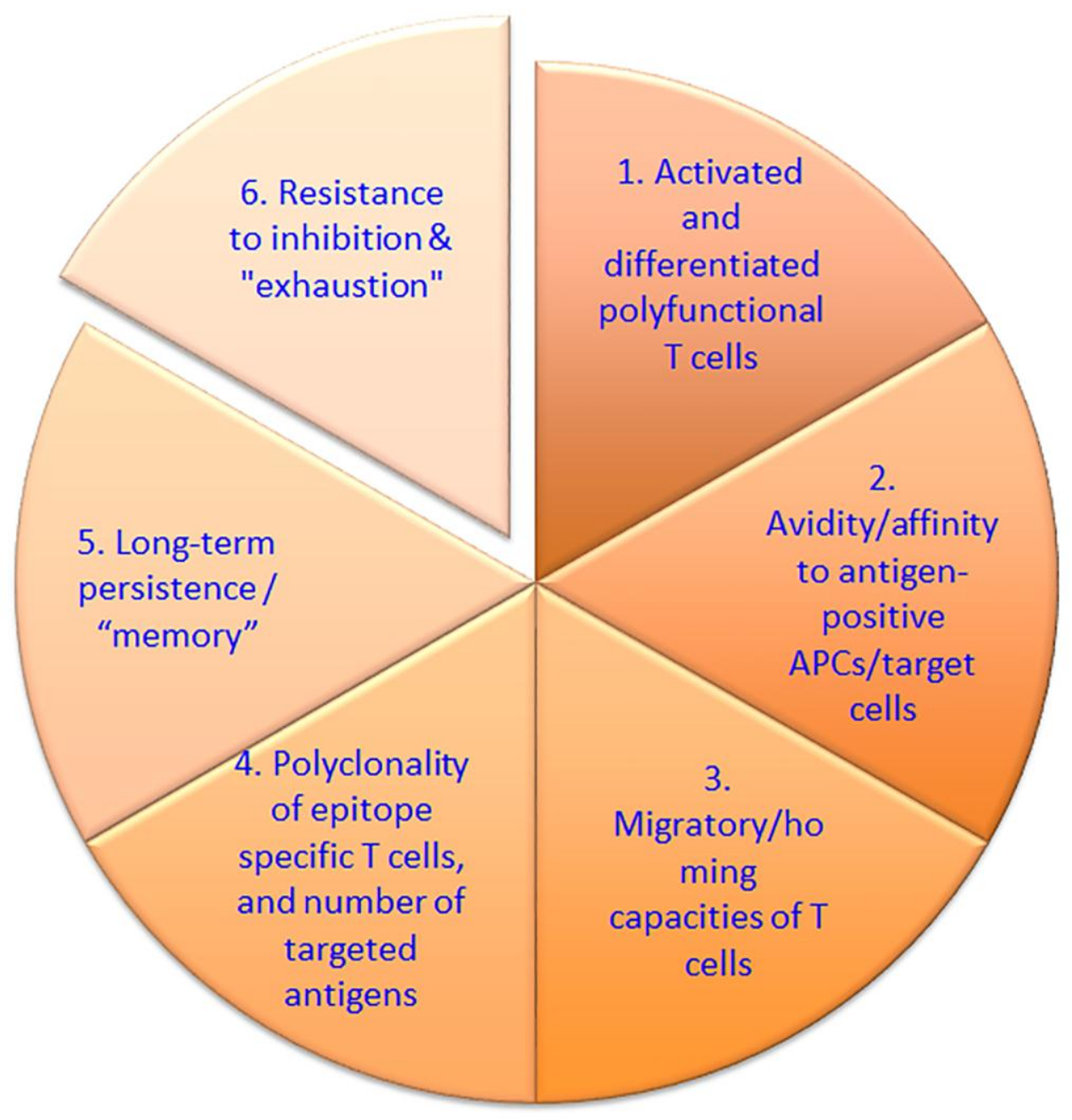




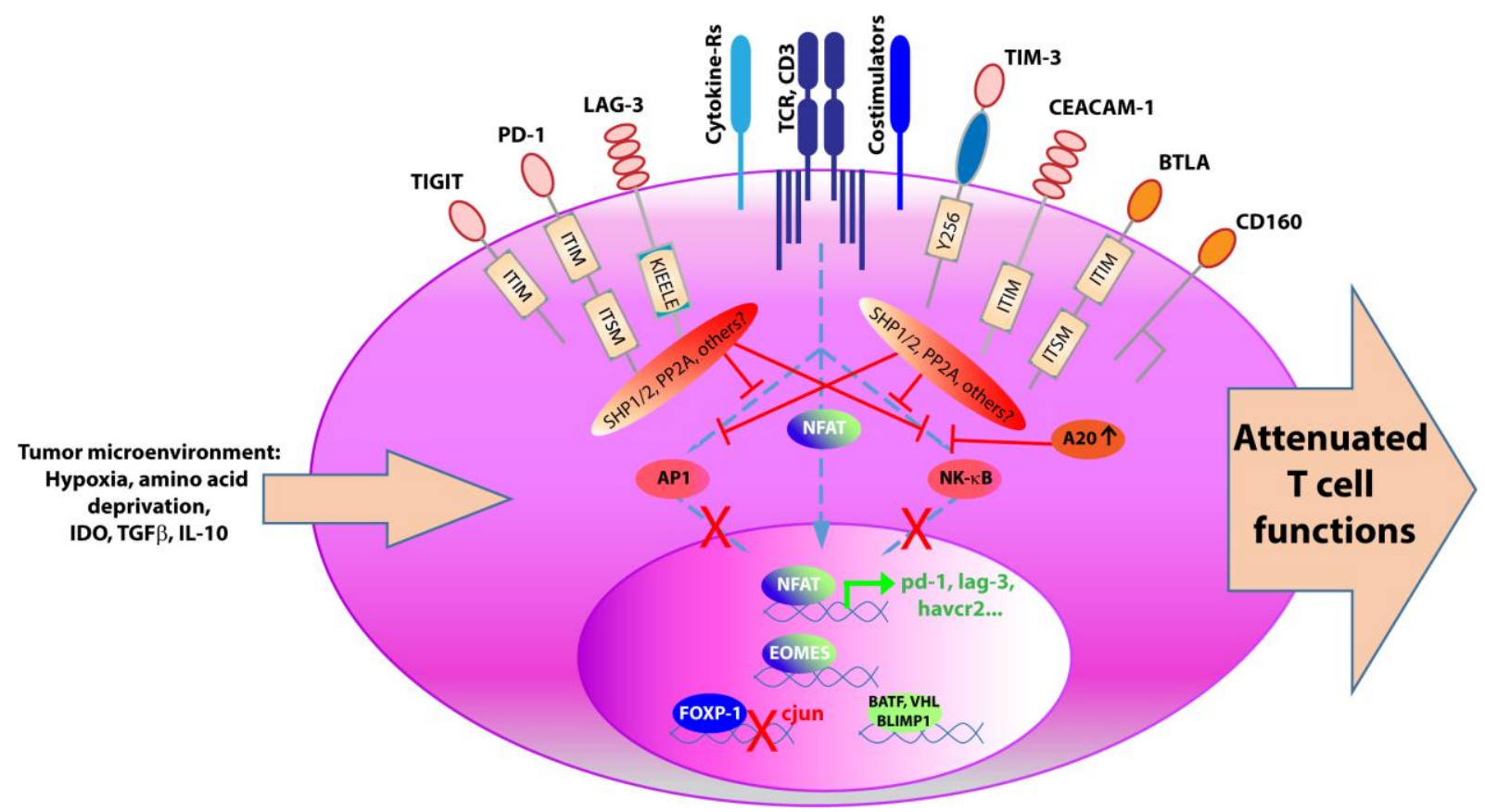




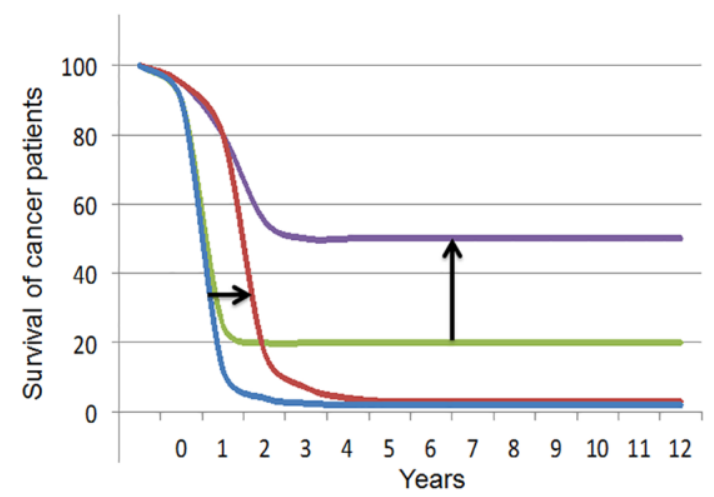

-Future

immunotherapy

-Current

immunotherapy

-Future tumor

targeted therapy

-Current tumor

targeted therapy 